\title{
Roles of Carbohydrate-Binding Module (CBM) of an Endo- $\beta-1,4-$ Glucanase (Cel5L) from Bacillus sp. KD1014 in Thermostability and Small-Substrate Hydrolyzing Activity ${ }^{\mathbb{S}}$
}

\author{
Jae Pil Lee ${ }^{1}$, Eun-Sun Shin ${ }^{2}$, Min Yeol Cho ${ }^{2}$, Kyung-Dong Lee ${ }^{3}$, and Hoon Kim ${ }^{1,2 *}$ \\ ${ }^{1}$ Department of Pharmacy, and Research Institute of Life Pharmaceutical Sciences, Sunchon National University, Suncheon 57922, Republic \\ of Korea \\ ${ }^{2}$ Department of Agricultural Chemistry, Sunchon National University, Suncheon 57922, Republic of Korea \\ ${ }^{3}$ Department of Oriental Medicine Materials, Dongshin University, Naju 58245, Republic of Korea
}

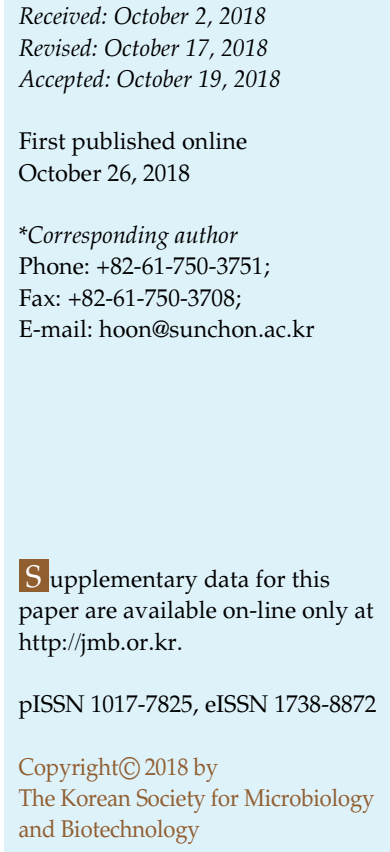

S upplementary data for this paper are available on-line only at http://jmb.or.kr.

pISSN 1017-7825, eISSN 1738-8872

Copyright(C) 2018 by

The Korean Society for Microbiology and Biotechnology

\begin{abstract}
An endo- $\beta$-1,4-glucanase gene, cel5L, was cloned using the shot-gun method from Bacillus sp.. The gene, which contained a predicted signal peptide, encoded a protein of 496 amino acid residues, and the molecular mass of the mature Cel5L was estimated to be $51.8 \mathrm{kDa}$. Cel5L contained a catalytic domain of glycoside hydrolase (GH) family 5 and a carbohydrate-binding module family 3 (CBM_3). Chromatography using HiTrap Q and CHT-II resulted in the isolation of two truncated forms corresponding to 50 (Cel5L-p50) and $35 \mathrm{kDa}$ (Cel5L-p35, CBM_3-deleted form). Both enzymes were optimally active at $\mathrm{pH} 4.5$ and $55^{\circ} \mathrm{C}$, but had different half-lives of 4.0 and $22.8 \mathrm{~min}$, respectively, at $70^{\circ} \mathrm{C}$. The relative activities of Cel5Lp50 and Cel5L-p35 for barley $\beta$-glucan were 377.0 and $246.7 \%$, respectively, compared to those for carboxymethyl-cellulose. The affinity and hydrolysis rate of $p$ NPC by Cel5L-p35 were 1.7 and 3.3 times higher, respectively, than those by Cel5L-p50. Additions of each to a commercial enzyme set increased saccharification of pretreated rice straw powder by 17.5 and $21.0 \%$, respectively. These results suggest CBM_3 is significantly contributing to thermostability, and to affinity and substrate specificity for small substrates, and that these two enzymes could be used as additives to enhance enzymatic saccharification.
\end{abstract}

Keywords: Bacillus sp. KD1014, GH5 endo- $\beta-1,4-$ glucanase, truncated enzymes, CBM, thermostability, saccharification

\section{Introduction}

Cellulosic biomasses are of particular interest as valuable raw materials for the production of cellulosic ethanol [1]. Complex polysaccharides can be hydrolyzed by cellulases such as endo- $\beta$-1,4-glucanase, exo- $\beta$-1,4-glucanase, and $\beta$ glucosidase. Among them, endo- $\beta-1,4$-glucanases, which are grouped into 13 glycoside hydrolase (GH) families; $5-9$, $12,44,45,48,51,74,124$, and 131 [2], play important roles in hydrolysis as they cleave internal glycosidic bonds in the chains [3]. Most of the enzymes grouped in GH families 5$9,12,44,45$, and 48 are cellulases acting on cellulose [4]. Of these, GH5 is the largest with more than 12,000 sequences in the Carbohydrate-Active Enzyme (CAZy) database (http:/ / www.casy.org) that are divided into 54 subfamilies. Most GH5 enzymes exclusively display endocellulase activity, but a few are exocellulases [5]. Based on published data, more than $60 \%$ of $\mathrm{GH}$ proteins are single proteins without non-catalytic accessory domains, such as carbohydratebinding modules (CBMs), and the rest were multidomain proteins with CBMs [6]. CBMs are classified into 83 families (http://www.casy.org), and CBM2, 3, and 6 are targeting cellulose [6].

Improvements in saccharification processes have been studied intensively in the contexts of lignocellulosic biorefinery processes and the production of lignocellulosic 
biofuels. Key process steps, such as the pretreatment of biomasses and enzymatic hydrolysis by enzyme cocktails and additives have been well investigated [1,7]. In addition, the enhancement of the enzymatic saccharification of cellulose processes using synergistic proteins including CBMs, has also been studied [8].

Several GH5 endo- $\beta$-1,4-glucanases cloned from Bacillus sp. have been characterized [9-13]. In the present study, cloning of an endo- $\beta$-1,4-glucanase, belonging to GH5 with a CBM_3, from Bacillus sp. KD1014 isolated from soil was conducted. Two truncated forms of the enzyme were purified, and CBM_3 roles in substrate specificity, thermostability, and carbohydrate binding ability were investigated. Finally, their abilities to enhance saccharification were analyzed using pretreated biomasses.

\section{Materials and Methods}

\section{Chemicals and Enzymes}

Lichenan (Icelandic moss) and commercial enzymes (Novozym 188 and Celluclast 1.5L) were obtained from Megazyme (Wicklow, Ireland) and Novozyme (Bagsvaerd, Denmark), respectively. Substrates such as carboxymethyl-cellulose (CMC) and $p$ nitrophenyl- $\beta$-D-cellobioside ( $p$ NPC), and other chemicals were from Sigma-Aldrich (USA).

\section{Cloning of a CMCase Gene and Analysis of the Gene}

For shot-gun cloning, genomic DNA was isolated from Bacillus sp. KD1014, which was previously isolated from soil [14]. Cloning of a gene for a CMC-degrading enzyme was conducted as previously described [15], except for using LBCT (LB containing $0.5 \%$ CMC and $0.008 \%$ trypan-blue) agar plates for tooth-picked transformants instead of the step for Congo red staining. The conserved regions were analyzed using BLAST at NCBI (http:/ / www.ncbi.nlm. nih.gov). Putative signal peptide was predicted by SignalP 4.1 in CBS (http:/ / www.cbs. dtu.dk/services/SignalP/) [16]. The molecular mass and multiple alignment of the encoded protein were analyzed using DNA/MAN (Lynnon Biosoft, version 4.11, Canada).

\section{Purification of the Enzyme}

The enzyme was isolated from the selected clone as previously described [15] with slight modification. Briefly, the crude extract was dialyzed against $50 \mathrm{mM}$ Tris- $\mathrm{HCl}$ buffer ( $\mathrm{pH}$ 8.0) and passed through a HiTrap Q column (5 ml, GE Healthcare, Sweden) using a linear $\mathrm{NaCl}$ gradient $(0-1.0 \mathrm{M})$. Active fractions were further purified using a CHT-II column (5 ml, Bio-Rad, USA) using a sodium phosphate buffer gradient (10-500 mM, pH 6.8). Protein concentrations were determined using the Bradford method [17], and the protein was analyzed by SDS-PAGE using $11 \%$ polyacrylamide gels [18].

\section{Enzyme Assay}

Enzyme activity was analyzed using $0.5 \% \mathrm{CMC}$ in $50 \mathrm{mM}$ sodium citrate buffer ( $\mathrm{pH}$ 5.5), as described previously [19], but at $50^{\circ} \mathrm{C}$. The amount of reducing sugar released was determined using the dinitrosalicylic acid (DNS) method [20]. To investigate the substrate specificity of Cel5L, activities were determined using $0.5 \%$ barley $\beta$-glucan, birchwood xylan, lichenan or laminarin. Its hydrolyzing activities for filter paper $(1 \mathrm{~cm} \times 1 \mathrm{~cm}$ strip $)$ and Avicel $(0.5 \%)$ were observed after $2 \mathrm{~h}$ at $50^{\circ} \mathrm{C}$. Hydrolyzing activities for $p$ NPG and $p$ NPC were assayed using $2.0 \mathrm{mM}$ of each substrate at $50^{\circ} \mathrm{C}$. One unit of hydrolyzing activity was defined as the amount of enzyme liberating $1 \mu \mathrm{mol}$ of reducing sugar or $p \mathrm{NP}$ per min.

\section{Activity Staining}

Enzyme activity was observed by activity staining after SDSPAGE, as described previously [15] with some modifications. Briefly, proteins in crude extract or fractions were separated in $11.0 \%$ SDS-polyacrylamide gels containing $0.2 \%$ CMC. Gels were then washed with $10 \%$ isopropanol for $30 \mathrm{~min}$ and then cleaned three times with the assay buffer $(\mathrm{pH} 5.5)$ for $30 \mathrm{~min}$, incubated at $50^{\circ} \mathrm{C}$ for $0.5 \sim 1 \mathrm{~h}$, stained with $0.1 \%$ Congo-red, and washed with $1 \mathrm{M} \mathrm{NaCl}$.

\section{Characterization of Enzymes}

Optimum temperature for the enzymes was determined by measuring enzyme activities at designated temperatures and thermostability was analyzed after pre-incubation of the enzymes [21]. Optimum $\mathrm{pH}$ levels for enzyme activity were determined using $50 \mathrm{mM}$ sodium citrate (pH 3.5-6.0) buffer. The influences of various cations on enzyme activity were determined as described previously [21].

\section{Binding with Insoluble Avicel}

Binding abilities of enzymes to carbohydrate polymer were analyzed as described previously with slight modification [22]. Briefly, the purified enzymes were added to $1.5 \%$ Avicel solution in $0.3 \mathrm{ml}$ of the assay buffer ( $\mathrm{pH} 5.5)$, mixed with shaking for $40 \mathrm{~min}$ on ice and centrifuged at $15,000 \times g$ for $10 \mathrm{~min}$ to remove enzymes bound to Avicel. Amounts of unbound enzymes were determined by measuring cellulase activity in supernatants.

\section{Saccharification of Pretreated Biomasses}

Enzymatic hydrolyses of reed (Phragmites communis) and rice (Oryza sativa) straw powders were carried out as previously described [15], but with purified enzymes rather than crude extracts. Briefly, pretreated reed or rice straw powders were suspended at $6 \%$ in $5 \mathrm{ml}$ of $50 \mathrm{mM}$ sodium citrate buffer ( $\mathrm{pH} 5.5)$ in $50 \mathrm{ml}$ tubes. The concentrations of the enzymes used were $0.2 \mathrm{U} / \mathrm{ml}$ of Celluclast $1.5 \mathrm{~L} ; 0.2 \mathrm{U} / \mathrm{ml}$ of Novozym 188; and $0.33 \mathrm{U} / \mathrm{ml}$ of Cel5L. Reactions were carried out for up to $72 \mathrm{~h}$ at $50^{\circ} \mathrm{C}$ with shaking at $150 \mathrm{rpm}$. Aliquots of the mixtures were withdrawn at designated times $(0,6,12,24,48$, and $72 \mathrm{~h})$ and 
centrifuged for $10 \mathrm{~min}$ at $12,000 \times g$. Amounts of soluble sugar released were measured using the DNS method [20]. All experiments were performed in duplicate.

\section{Results and Discussion}

\section{Cloning and Characterization of the CMCase Gene}

One CMCase positive clone, ES 8-10, was selected on LBCT agar plates. In the insert DNA of $2.58 \mathrm{~kb}$, an open reading frame (ORF) of 1,491 bp was identified as an endo$\beta$-1,4-glucanase gene with high similarities to glycosyl hydrolase family 5 (GH5) enzymes and named cel5L. The gene was identified to encode a protein of 496 amino acid residues with a signal peptide of 29 amino acid residues. The molecular mass of mature Cel5L was calculated to be $51.8 \mathrm{kDa}$. A comparison with previously reported enzymes revealed a protein sequence with high similarity to CMCase of B. subtilis BSE616 (98\%) (GenBank Accession No. D01057.1, BAA00859.1) [9], 97\% similarity to the endoglucanase (Cel5A) of B. subtilis BME-15 (FJ172348, ACI15227) [23], 92\% similarity to the endoglucanase of B. subtilis DLG (M16185, AAA22496.1) [24], and 62\% similarity to the endoglucanase (Egl) of Bacillus sp. KSMN252 (AB057671.1, BAB62295) [25]. Cel5L was found to be modular endoglucanase to contain a catalytic domain (residues 50-293), to belong to glycoside hydrolase family 5 (GH5), and to possess one CBM_3 domain (353-434 $\left.4^{\text {th }}\right)$ at the C-terminal end of the catalytic domain (Fig. 1A).

Cel5L was found to belong to GH5 subfamily 2 (GH5-2), in which the endoglucanases of B. subtilis are grouped. Several residues are conserved in the GH5 catalytic domain of Cel5L, that is, catalytic residues Glu169 and Glu257, which act as proton donor and nucleophile, respectively, and Trp69, Arg92, His131, Asn168, Trp207, and Tyr231 residues [13, 23, 26, 27] (Fig. 1B). When other subfamilies of GH5, i.e., GH5-1 endoglucanase (Cel5B) of Thermobifida fusca TM51 (AY298814, AAP56348) and GH5-4 bifunctional cellulase of B. halodurans TSLV1 (the same as BAB04322 cited by 28) were blasted together, Arg92, His131, Asn168, and Tyr231 and the two catalytic residues were found to be strictly conserved (Fig. 1B). In addition, Val126, Pro170 in the NEP motif, Asn175, Asp221, Gly259 in the EwG motif, Phe270, and Trp291 residues were also found to be conserved in the catalytic domain.

The CBM of Cel5L was linked to the C-terminus of the GH5 catalytic domain, as is likely the case with most GH5 cellulases [29]. In some GH5 cellulases, two CBMs are linked to the catalytic domain, such as in Cel5A of Bacillus sp. 1139, which contains CBM17 and 28 in tandem [30].

Cel5L expressed in E. coli was predicted to have the same signal peptide as that in wild-type Bacillus sp. by SignalP 4.1 analysis, and based on this prediction, the molecular mass of mature Cel5L was $51.8 \mathrm{kDa}$.

The nucleotide sequence of cel5L has been deposited in the GenBank under the accession number MH923517.

\section{Purification of Two Truncated Enzymes}

Cel5L was purified from the transformant using HiTrap $\mathrm{Q}$ and CHT-II chromatography. The amount of enzyme bound by the High-Q column was much less than that bound by the HiTrap Q column (data not shown). When proteins in extract were separated using the HiTrap Q column, one activity peak was observed (Fig. S1), and when pooled active fractions were further purified using the CHT-II column, two partially resolved activity peaks were observed (Fig. S1). To check the enzyme species, CMCase activities were analyzed using a crude extract of the transformant by activity staining after SDS-PAGE and renaturation methods. Two active bands were observed, and these proteins were named $\mathrm{P} 1$ and $\mathrm{P} 2$, respectively (Fig. 2A). Enzyme activity of P1 was greater than that of P2. The active bands observed represented truncated forms produced by internal proteolytic cleavages, as has been reported for other heterologous gene expressions [15, 3134]. Fractions eluted from the CHT-II column revealed P2 was eluted before $\mathrm{P} 1$, which corresponded to molecular masses of 35 and $50 \mathrm{kDa}$, respectively. Both forms were pooled and named Cel5L-35 and Cel5L-50, respectively (Fig. 2B). The two forms were nearly homogeneous, though Cel5L-35 appeared along with minor bands. The average

Table 1. Purification of two truncated endo- $\beta-1,4$-glucanases in the transformant cloned from Bacillus sp. KD1014.

\begin{tabular}{lccccccc}
\hline \multicolumn{1}{c}{ Procedure } & Enzyme & $\begin{array}{c}\text { Volume } \\
(\mathrm{ml})\end{array}$ & $\begin{array}{c}\text { Total protein } \\
(\mathrm{mg})\end{array}$ & $\begin{array}{c}\text { Total activity } \\
(\mathrm{U})\end{array}$ & $\begin{array}{c}\text { Specific activity } \\
(\mathrm{U} / \mathrm{mg})\end{array}$ & $\begin{array}{c}\text { Purification } \\
(\text { fold })\end{array}$ & $\begin{array}{c}\text { Yield } \\
(\%)\end{array}$ \\
\hline Supernatant & & 5.0 & 17.8 & 212.7 & 11.9 & 1.0 & 100 \\
Hi-Trap chromatography & & 7.5 & 0.82 & 54.7 & 67.0 & 5.6 & 25.7 \\
CHT-II chromatography & Cel5L-p50 & 2.0 & 0.10 & 11.6 & 110.5 & 9.3 & 5.4 \\
& Cel5L-p35 & 3.5 & 0.14 & 11.8 & 86.2 & 7.2 & 5.5 \\
\hline
\end{tabular}


A

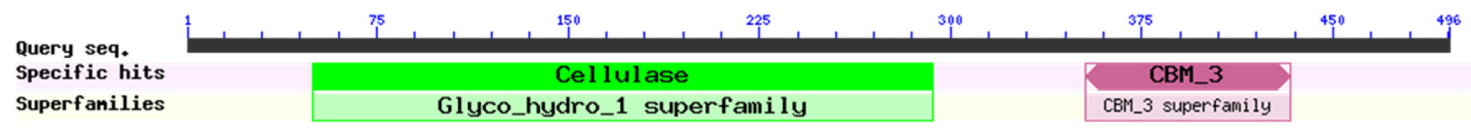

B

\begin{tabular}{|c|c|c|}
\hline & 0 & \\
\hline$=15 \mathrm{~L}$ & MRRSISIFITCLLITLLTMGGMLASEASAAGTKTPVAKNGLISIR & 74 \\
\hline A. A.00859.1 & SAAGTKTPVAKNGQLISIKGTCQLVNR & 74 \\
\hline R050177.1 & 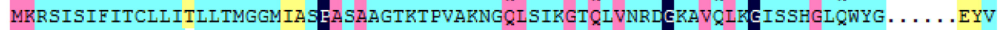 & 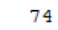 \\
\hline A22496.1 & MRRSISIFITCLLIAVLTMGGLIPSEASAAGTKTPVAKNGQISIKGICLLVNRIGKAVQLKEISSHGLQWYY. & 74 \\
\hline B 62295 & MKSRKKIIPICMALILTLALLMTGN PVADN . . SVVGQNGCOLISGSCQLVNQNGR & 72 \\
\hline P56348.1 & LTRRLRAGAAAIAI GASALIPLTSSEAAASG . . ....TADẂLHTDGNRIVDSZGG & 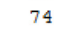 \\
\hline B04322.1 & 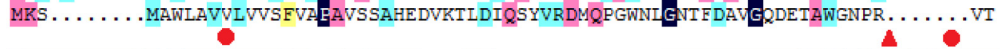 & $G E$ \\
\hline$=15 \mathrm{~L}$ & NKDSLKWLRDDWEITVFRAMYTA. . DGGYIDN. . . . PS. & 134 \\
\hline BAA00859.1 & NKDSLKWLRDDWGITVFEAMMYTA. .DGGIIDN.....PS.. & 134 \\
\hline 050177.1 & NKDSLKWLRDLWGITVHAAMYTA. .DGGYIDN. . . . PS. & 34 \\
\hline A.22496.1 & NKDSLRWLRDDWEITVHAAMYTA..DGGYIDN $\ldots \ldots$ PS $\ldots \ldots \ldots \ldots \ldots$ VKNNVREAVEAAKELGIYVIIDWHILN & 134 \\
\hline BB62295 & NYDSIKWLRDDWEITVHRAAMYTS $\ldots$ SGGYIQD $\ldots$ RS $\ldots \ldots \ldots \ldots \ldots$ VRDKVIESIEVAIDLGIYVIILWHILS & 132 \\
\hline P56348.1 & NIEDITSAMAERGINMVR VPISTQ . . LLLEWKNGQAGPSGVNEYVNPELAGMNTLEVFDYWLQLCEEYGLKVMLDVHSAE & \\
\hline $\mathrm{AB} 04322.1$ & $\cdots$ RELIEQIADAGYKSIRIPVTWENRIGGAPDYP $\ldots \ldots \ldots \ldots \ldots \ldots$ IDPQFLNRVDQVVQWALEELIYUMINLHHDS & 128 \\
\hline e15L & 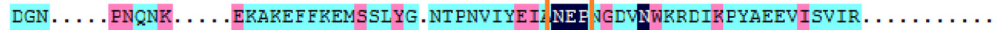 & 192 \\
\hline AA00859.1 & . . EKAKEFFKEMSSIYG.NTPNVIYEI/ NEE JGDVNWKRDIKPYAEEVISVIR. & 192 \\
\hline 050177.1 & DGN $\ldots \ldots$ PNQNK $\ldots \ldots$ ERAREF FREMSSLYG. NT PNVIYEII/NEF JGDVNWRRDIRPYAEEVISVIR. & \\
\hline AA22496.1 & 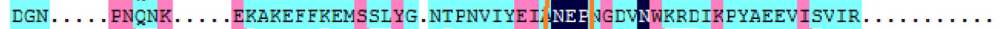 & 192 \\
\hline BB62295 & 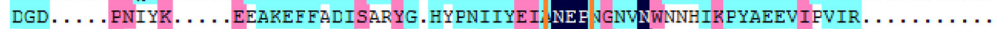 & 190 \\
\hline P56348.1 & ADNSGHYYPVWYKGDITTEDFYTAWEWVTERYKNNDTIVAADI NEF GGRAETPRAKWDGSTDIDNFKHVCETAGKRIL & 232 \\
\hline AB04322.1 & WLWIYEMEHNYNG . . VMVKYRSLWEQISNHFRDYPTKLMFES NER KFSQWWGEIRENHHALLDDLNTVFFEIVRQSGG & 205 \\
\hline$=15 \mathrm{~L}$ & ...KNDPDNIIIVGTGTWSQDVNDAADDQLKLANVMYALHAŸAGTHGQFLRDKANYALSKG. & 250 \\
\hline A00859.1 & 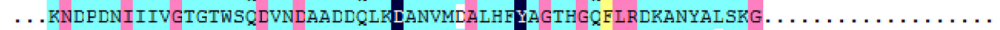 & 250 \\
\hline R050177.1 & 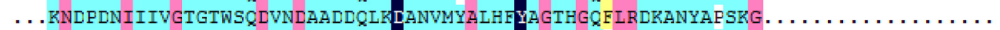 & 250 \\
\hline A22496.1 & ...KNDPDNIIIVGTGTWSQDVNDAADDQLKLANVMYALHAYAGTHGQSLRDKANYALSKG. & 250 \\
\hline B 62295 & NNPLZLENVMYAFHFYAGTHGQMLRDRVDYALSCG. & 248 \\
\hline P56348.1 & A. . INPNMLILCEGIEIYYKDGQDWSSTDGRD $\ldots \ldots \ldots$ YYSTWWGGNLRGVADHPVDIGAHQDQLVYSPHDYGPSVFE & 302 \\
\hline 2.1 & QNDIRPLVLPTMETATSQPLLNNLYQTIDKIDPPNLIATVHYYGFWPFSVNIAGYTRFEENSKQE $\ldots \ldots \ldots \cdots \cdots$ & 270 \\
\hline$=15 \mathrm{~L}$ & AFIFV] Ë̄ETSDASGNGG. & 278 \\
\hline 9.1 & . ARIFV] EREELSDASGNGG. & 278 \\
\hline 2050177.1 & ...AFIFV] BWELSDASGNGG. & 278 \\
\hline A22496.1 & ...APIFV] BWEISDASGNGG. & 278 \\
\hline B 62295 & ... AAIFVSEWG ESAATGDGG. & 276 \\
\hline AP56348.1 & QPWFE GEWNRQTLTEDVWR PNWLYIHEDDIAFLIIC BWG GFLDGGDNE KWMTALLRSLI IDEKMMHHT FWALNPNSG . . . & 377 \\
\hline $\mathrm{AB} 04322.1$ & 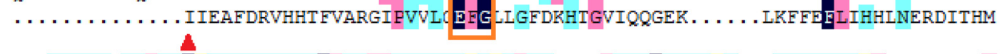 & 330 \\
\hline $15 \mathrm{~L}$ & ..KYIDSKTISWVI & 341 \\
\hline 9.1 & . . RYLDSKTISWVNWNLSDKÇESSSALRPGASKTGGWRLSDISA. . . . SGT FVRENILG. . . TKDSTKDIP. & 341 \\
\hline 2050177.1 & ..KYLDSKTISWVYWLLSDRQESSSZIRPGASRTGGWRLSDISA . . . . SGTFVRESILG . . . TKDSTKDIP. & 341 \\
\hline A22496.1 & ..NYLDSKNISWVNWNLSDKÇESSSAIRPGASKTGGWPLTDLTA $\ldots .$. SGTHVRENIRG . . TKDSTKDVP. & 341 \\
\hline AB 62295 & . . DWMDERNLSWANWSLTHKAESSARLMPGANPRGNWTAAEISP $\ldots$. SGA FVREAIRSSS. PPSQPPSEP $\ldots$ & 341 \\
\hline AP56348.1 & . DTGGLINYDWTTRDDEAKYAFLKARLWQDANGKFVGDHDVPLGGVGSTTGVSINQYYGGGGPSQPPTEPTEPPTEPTE & 455 \\
\hline $\mathrm{AB} 04322.1$ & LWDNGQHFNRHTY WYDQEL FDMMRASWEGRSSVAESNFIYLKQGDRIADATVSLQLHGNELTGLRANGQR $\ldots \ldots \ldots$ & 401 \\
\hline e15L & NVD. CDYAREGGNVT & 417 \\
\hline AA00859.1 & ENG. . ISVQYRAGDGSMNSNQIRPQLQIKNNGNTIVDLKDVTARYWYNAKNKGQNVD. CDYZQLGCGNVT & 417 \\
\hline 8050177.1 & TPSKDKFTQENG . . . ISVQYRAGDGSMNSNQIRPLLCIKNNGNITVDLKDVTARYWYKAKNKGQNVD. CDYRQIGCGNVT & 417 \\
\hline A.22496.1 & EKG ...VSVQYKAGDGRVNSNQIRPQLHIKNNGNZTVDLRDVTARYWYNVKNKGQNFD. CDYAQAGCGNLT & 417 \\
\hline B62295 & ..VYTGG.EIVTYDGQLWRAQWWTQGQAPGQ ... & 404 \\
\hline 8.1 & JSLAADDSQIAPGLRLVNTGSSTVDLADVEIHYYFTNEPGGTLQFTCDWZQVGCANVN & 535 \\
\hline B04322.1 & $\ldots$ LIPGQDYELN $\ldots$. GERLTVKAHVLSA IASSGTLGTNGMVT EFNRGADWHFRVNTYRTP $\ldots \ldots$ VI $Q S T Q G H V S$ & 467 \\
\hline $15 \mathrm{~L}$ & . DY & \\
\hline 1200859.1 & YKFVTLHKPKQGADTYLELGFRNGTLAFGASTGNIQLRLHNDDWSNYAQSG. . & 487 \\
\hline 7.1 & HKFVTLHKPKQGADTYPELGFKNGTLAPGASTGNIQLRLHNDDWSNYAQSG $\ldots \ldots \ldots \ldots$ DYSFFKSNTFKTTKKITLY & 487 \\
\hline A.22496.1 & CGTLSPGASTGNIQLRLHNDDWSNYAQSG $\ldots \ldots \ldots \ldots$ DYSFFCSNTFKTTKRITLY & 487 \\
\hline BB62295 & SSLPPSEPEP. . PTEPEPPSEPEPPSEPEPEPPSEPEPPSDPGTYPAWSASQIYTGGEIVSYSGQLWRAKWWTQNQTPG & 482 \\
\hline $\mathrm{P} 56348.1$ & ..SLAFGAST.ELQGRIHTANWANFDESD. . & 601 \\
\hline $\mathrm{AB} 04322.1$ & NFSIPASFNGNSLATMEAVYVDGGNAGPQDWTSFKEFGYAFSPSYDANEMKLTEAFFREVRDGEVRLTFHFWSGETVNYT & 547 \\
\hline$t \sqrt{2}$ & & 499 \\
\hline AA00859.1 & LQGKI & 499 \\
\hline 50177.1 & CGK & 499 \\
\hline A22496.1 & HQGKL IWGTEPN & 499 \\
\hline 62295 & $\mathrm{DQ} \cdot \mathrm{Y}$ & 492 \\
\hline 348.1 & LGGTLVWGTPPA & 613 \\
\hline 304322.1 & IIKNGNQVTGIA & \\
\hline
\end{tabular}

Fig. 1. Putative conserved domains of Cel5L (A) and multiple alignment of the amino acid sequences of Cel5L and other endo- $\beta$ 1,4-glucanases (B).

Asterisks represent catalytic residues. Closed and open red circles represent conserved amino acid residues in GH5-2 members and in GH5-1 and GH5-4 blasted together, respectively. Closed triangles represent conserved residues. The inverted long triangle indicates the tentative cleavage site of a signal peptide in Cel5L as determined by SignalP4.1. Conserved motifs are represented as orange boxes. CBM_3, carbohydrate binding module_3. 
A

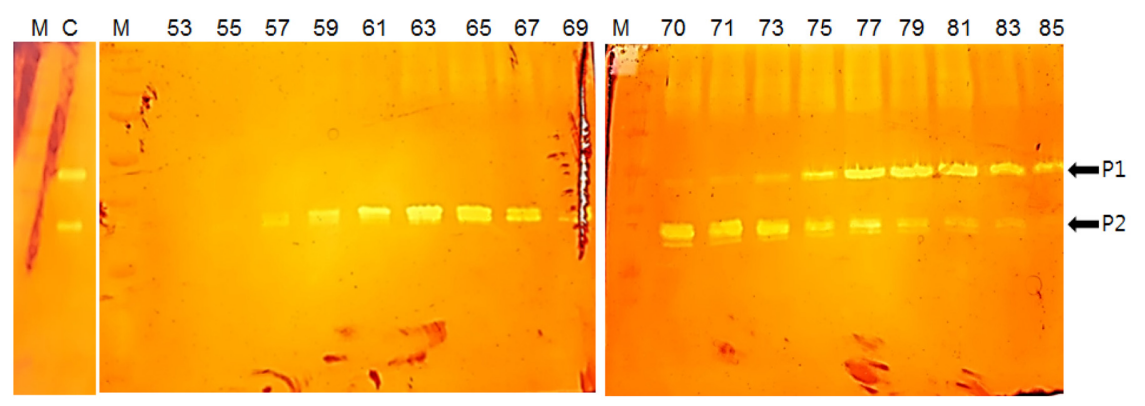

B

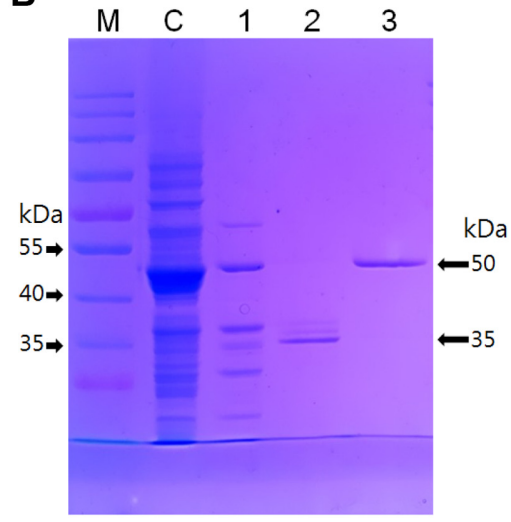

Fig. 2. Staining of enzyme activities after SDS-PAGE and renaturation of fractions eluted by CHT-II chromatography (A), and SDS-PAGE of the purified truncated enzymes (B).

(A): $\mathrm{C}$ represents crude extract. Numbers at the tops of figures represent fraction numbers. (B): $\mathrm{M}$, molecular weight markers; $\mathrm{C}$, crude extract of the clone ES 8-10; 1, active fractions pooled from HiTrap chromatography; 2 and 3, active fractions corresponding to Cel5L-p35 and Cel5L-p50, respectively, obtained by CHT-II chromatography. For activity staining, the gel was made by adding $0.5 \%$ CMC, whereas the SDS-PAGE gel was made without $\mathrm{CMC}$ to enable accurate molecular mass determination.

specific activities of Cel5L-p50 and Cel5L-p35 were 110.5 and $86.2 \mathrm{U} / \mathrm{mg}$ protein, respectively (Table 1).

Based on estimated molecular masses, it was predicted Cel5L-50 and Cel5L-35 were composed of approximately 455 and 318 amino acid residues, respectively, i.e. $30-484^{\text {th }}$ and $30-347^{\text {th }}$ residues, respectively. Considering the size of the CBM_3 domain (353-434 $\left.4^{\text {th }}\right)$, Cel5L-50 contained complete CBM_3, whereas Cel5L-p35 contained only a catalytic domain without entire CBM_3, presumably due to internal proteolytic cleavage, as has been reported for other endoglucanases in E. coli $[15,19,35]$. Actually, as the purification progressed, an extra minor band corresponding to a smaller molecular mass was observed by second column chromatography in activity stained gel (Figs. 2A and $2 \mathrm{~B}$ ). These truncation products have also been observed for other modular or multimodular enzymes [15, 31-34].

\section{Substrate Specificities of the Truncated Enzymes}

The relative activities of Cel5L-p50 and Cel5L-p35 for barley $\beta$-glucan ( $\beta-1,3-1,4$-glucan) were 377.0 and $246.7 \%$, respectively, as compared with CMC ( $\beta$-1,4-glucan) (Table 2). These higher activities for barley $\beta$-glucan than CMC resembled those of GH5-2 endoglucanases [29,36] and a fungal GH5-5 cellulase GtCel5 of Gloeophyllum trabeum [2]. However, the two enzymes showed low but moderate hydrolytic activities, 35.0 and $32.7 \%$, respectively, for lichenan (another type of $\beta-1,3-1,4$-glucan with a different ratio of $\beta-1,3$ to $\beta-1,4)$. This result was similar to that of BlCel5B of B. licheniformis [37], but differed from those of
BsCel5A of B. subtilis 168 and the GtCel5 of G. trabeum, which had higher lichenase activity than CMCase activity $[2,11]$, and the Cel5B of T. fusca with undetectable lichenases activity [38]. Both Cel5L-p50 and Cel5L-p35 showed low activities for laminarin ( $\beta-1,3-1,6$-glucan), however, the activity of Cel5L-p35 was 2.8 times higher than that of Cel5L-p50 (71.6\% and 25.2\%, respectively). No or negligible activities were observed toward birchwood xylan ( $\beta-1,4$-xylose), Avicel, or filter paper (Table 2), as has been reported for Cel5A of B. subtilis BME-15 and the GtCel5 [2,23], and the BsCel5A with undetectable Avicelase activity [29], but not for GH5 cellulase of B. amyloliquefaciens DL-3, which has significant Avicelase activity [10].

Table 2. Substrate specificities of Cel5L-p50 and Cel5L-p35.

\begin{tabular}{lcc}
\hline \multirow{2}{*}{ Substrate } & \multicolumn{2}{c}{ Relative activity $(\%)$} \\
\cline { 2 - 3 } & Cel5L-p50 & Cel5L-p35 \\
\hline CMC & 100 & 100 \\
Barley $\beta$-glucan & $377.0 \pm 0.63$ & $246.7 \pm 1.97$ \\
Lichenan & $35.0 \pm 0.65$ & $32.7 \pm 0.25$ \\
Laminarin & $25.2 \pm 0.73$ & $71.6 \pm 0.57$ \\
Xylan & $\mathrm{ND}$ & $\mathrm{ND}$ \\
Avicel & $\mathrm{ND}$ & $6.9 \pm 0.74$ \\
Filter & $0.85 \pm 0.18$ & $1.4 \pm 0.35$ \\
& & $191.9 \pm 1.04$ \\
$p$ NPC & $58.9 \pm 0.38$ & $1.5 \pm 0.59$ \\
$p$ NPG & $\mathrm{ND}$ &
\end{tabular}

$\mathrm{ND}$, not detectable 

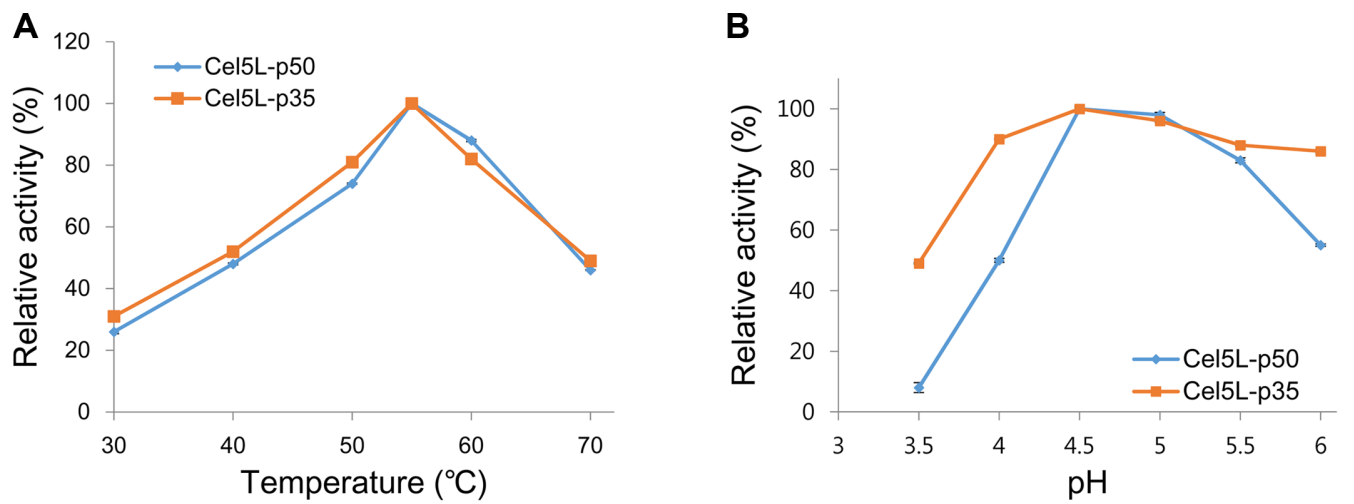

C
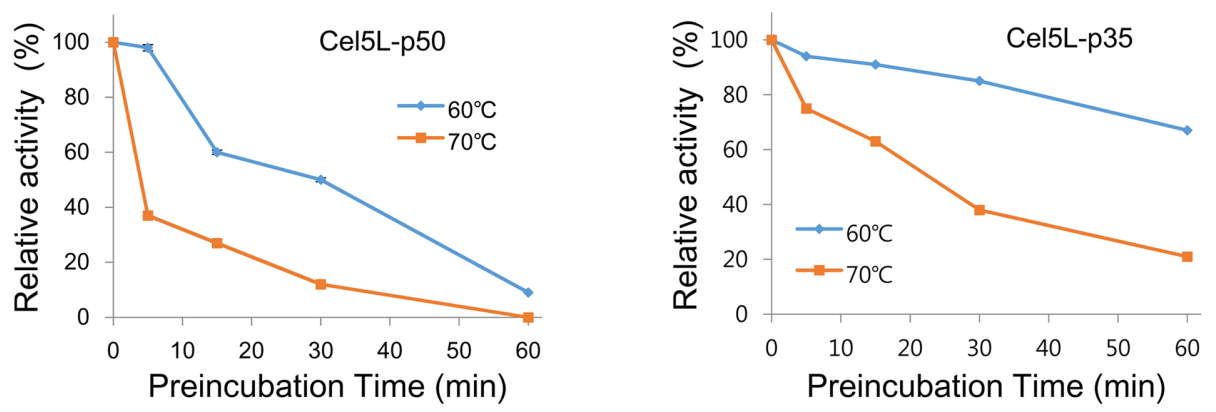

Fig. 3. Effects of $\mathrm{pH}(\mathbf{A})$ and temperature (B) on the enzyme activities of Cel5L-p50 and Cel5L-p35 and on their thermostabilities after preincubation at 60 and $70^{\circ} \mathrm{C}(\mathrm{C})$.

Enzyme activities were measured using $50 \mathrm{mM}$ Na-citrate buffer.

Interestingly, Cel5L-p50 and Cel5L-p35 hydrolyzed a small substrate of $p \mathrm{NPC}$ with activities of 58.9 and 191.9\%, respectively, indicating the hydrolysis of $p$ NPC by Cel5Lp35 was 3.3 times higher than that by Cel5L-p50. Substrate specificities of the enzymes showed Cel5L was able to efficiently hydrolyze $\beta-1,4$ linkages of mixed-linked $\beta-1,3$ 1,4 -glucans such as barley $\beta$-glucan, but with strict $\beta-1,3$ to $\beta-1,4$ ratio sensitivity, which may have been due to the higher ratio of $\beta-1,4$ to $\beta-1,3$ linkages in $\beta$-glucans than in lichenans [39].

\section{Enzymatic Properties of the Truncated Enzymes}

Cel5L-p50 and Cel5L-p35 showed the characteristics of acidic enzymes with maximal CMCase activity at $\mathrm{pH} 4.5$ (Fig. 3A), similar to an acidic cellulase Cel-1 of buffalo rumen metagenome [40], though Cel5L-p35 was more resistant to $\mathrm{pH}$ changes than Cel5L-p50. Regarding optimum temperature, Cel5L-p50 and Cel5L-p35 both exhibited maximal $\mathrm{CMCase}$ activities at $55^{\circ} \mathrm{C}$ and showed similar activity/temperature characteristics (Fig. 3B). At $70^{\circ} \mathrm{C}$, the those of Cel5L-p50 and Cel5L-p35 were about half activities of maximal activities, 46.2 and $48.8 \%$, respectively. When compared with other GH5-CBM_3 cellulases, the optimum temperature of Cel5L-p50 and Cel5L-p35 was similar to that of Cel5A of B. subtilis BME-15 and the cellulase of $B$. amyloliquefaciens DL-3 (both $50^{\circ} \mathrm{C}$ ). However, optimum $\mathrm{pH}$ was similar to that of Cel5A ( $\mathrm{pH} 5.0)$, but quite different from that of the cellulase of B. amyloliquefaciens DL-3 $(\mathrm{pH}$ 7.0) $[10,23]$.

Cel5L-p50 and Cel5L-p35 retained 50.0 and $85.0 \%$ of their activities after $30 \mathrm{~min}$ of preincubation of each enzyme at $60^{\circ} \mathrm{C}$ (Fig. 3C). The half-lives of Cel5L-p50 and Cel5L-p35 activities were 4.0 and $22.8 \mathrm{~min}$ at $70^{\circ} \mathrm{C}$, which were comparable to the half-life of Cel5B of T. fusca $(\sim 8 \mathrm{~min})$ [38]. Truncation of CBM_3 by complete deletion from Cel5L increased thermal stability, as was observed for the endoglucanase of B. subtilis JA18 after deletion of CBM_3 [41]. During storage at $4^{\circ} \mathrm{C}, \mathrm{Cel} 5 \mathrm{~L}-\mathrm{p} 50$ proved to be less stable than Cel5L-p35 (data not shown).

The effects of mono- and divalent cations on Cel5L-p50 and Cel5L-p35 were not significant, with the exceptions of $\mathrm{Mn}^{2+}, \mathrm{Co}^{2+}, \mathrm{Cu}^{2+}$, and $\mathrm{Ba}^{2+}$ (Table 3). Cel5L-p50 and Cel5Lp35 were inhibited by 40.8 and $50.0 \%$, respectively, by $\mathrm{Mn}^{2+}$ at $5 \mathrm{mM}$, but the degree of this inhibition was not 
Table 3. Effects of cations on the activities of Cel5L-p50 and Cel5L-p35.

\begin{tabular}{|c|c|c|c|}
\hline \multirow{2}{*}{ Cation } & \multirow{2}{*}{$\begin{array}{l}\text { Concentration } \\
(\mathrm{mM})\end{array}$} & \multicolumn{2}{|c|}{ Relative activity (\%) } \\
\hline & & Cel5L-p50 & Cel5L-p35 \\
\hline Control & & 100 & 100 \\
\hline \multirow[t]{2}{*}{$\mathrm{NaCl}$} & 2 & $46.1 \pm 1.38$ & $98.6 \pm 0.62$ \\
\hline & 5 & $123.1 \pm 0.61$ & $116.1 \pm 0.44$ \\
\hline \multirow[t]{2}{*}{$\mathrm{KCl}$} & 2 & $47.9 \pm 1.10$ & $90.9 \pm 1.00$ \\
\hline & 5 & $124.8 \pm 0.25$ & $116.9 \pm 0.44$ \\
\hline \multirow[t]{2}{*}{$\mathrm{MgCl}_{2}$} & 2 & $58.0 \pm 0.55$ & $98.5 \pm 0.69$ \\
\hline & 5 & $119.3 \pm 0.86$ & $112.2 \pm 0.15$ \\
\hline \multirow[t]{7}{*}{$\mathrm{MnCl}_{2}$} & 0.01 & $88.9 \pm 1.07$ & $88.9 \pm 0.24$ \\
\hline & 0.02 & $73.4 \pm 1.25$ & $81.8 \pm 1.43$ \\
\hline & 0.1 & $41.2 \pm 0.15$ & $48.2 \pm 0.29$ \\
\hline & 0.5 & $50.7 \pm 0.30$ & $50.9 \pm 0.59$ \\
\hline & 1 & $53.2 \pm 0.45$ & $49.6 \pm 0.15$ \\
\hline & 2 & $42.6 \pm 0.67$ & $56.4 \pm 0.80$ \\
\hline & 5 & $50.0 \pm 1.34$ & $59.2 \pm 1.44$ \\
\hline \multirow[t]{2}{*}{$\mathrm{CaCl}_{2}$} & 2 & $66.0 \pm 1.38$ & $96.8 \pm 0.39$ \\
\hline & 5 & $100.9 \pm 0.49$ & $105.4 \pm 0.15$ \\
\hline \multirow[t]{2}{*}{$\mathrm{CuCl}_{2}$} & 2 & $160.9 \pm 1.38$ & $122.0 \pm 0.62$ \\
\hline & 5 & $166.6 \pm 0.74$ & $142.6 \pm 0.65$ \\
\hline \multirow[t]{2}{*}{$\mathrm{CoCl}_{2}$} & 2 & $48.1 \pm 0.83$ & $61.6 \pm 0.77$ \\
\hline & 5 & $49.4 \pm 0.49$ & $60.1 \pm 0.07$ \\
\hline \multirow[t]{2}{*}{$\mathrm{BaCl}_{2}$} & 2 & $79.2 \pm 0.83$ & $86.0 \pm 0.46$ \\
\hline & 5 & $125.8 \pm 0.98$ & $112.9 \pm 0.29$ \\
\hline \multirow[t]{2}{*}{$\mathrm{FeCl}_{2}$} & 2 & $76.7 \pm 1.10$ & $83.7 \pm 0.69$ \\
\hline & 5 & $97.4 \pm 0.25$ & $98.8 \pm 0.51$ \\
\hline \multirow[t]{2}{*}{$\mathrm{ZnCl}_{2}$} & 2 & $73.5 \pm 0.55$ & $87.9 \pm 0.77$ \\
\hline & 5 & $106.0 \pm 0.61$ & $104.0 \pm 1.02$ \\
\hline
\end{tabular}

concentration-dependent and exhibited a saturation pattern at $0.01 \sim 5.0 \mathrm{mM}$. The enzymes were inhibited by 33.3 and $39.2 \%$, respectively, by $\mathrm{Co}^{2+}$ at $2 \mathrm{mM}$, and by 42.6 and $48.28 \%$, respectively, at $5 \mathrm{mM}$. However, both enzymes were stimulated to 161.0 and 132.6 , respectively, by $\mathrm{Cu}^{2+}$ at $2 \mathrm{mM}$, and increased to 215.3 and $176.7 \%$, respectively, by $\mathrm{Cu}^{2+}$ at $5 \mathrm{mM}$. Finally, Cel5L-p50 activity was increased to $135.2 \%$ by $\mathrm{Ba}^{2+}$ at $5 \mathrm{mM}$. The inhibitions of Cel5L-p50 and Cel5L-p35 by $\mathrm{Mn}^{2+}$ and $\mathrm{Co}^{2+}$ were similar to those of the cellulase of B. amyloliquefaciens DL-3 [10], but unlike those of GH5 endoglucanase EG5C of Paenibacillus sp. IHB B 3084 [42], and the bifunctional GH5 cellulase of B. halodurans TSLV1 [28], which were enhanced by these ions. Activations of both enzymes by $\mathrm{Cu}^{2+}$ were similar to those of EG5C and the bifunctional cellulase $[28,42]$. Comparisons of cation
Table 4. Kinetic parameters of Cel5L-p50 and Cel5L-p35 for $\mathrm{CMC}$ and $p$ NPC.

\begin{tabular}{cccc}
\hline Enzyme & Substrate & $\mathrm{K}_{\mathrm{m}}{ }^{*}$ & $\mathrm{~V}_{\max }(\mathrm{U} / \mathrm{mg}$ protein) \\
\hline Cel5L-p50 & CMC & $0.77 \pm 0.094$ & $143.3 \pm 8.2$ \\
& $p$ NPC & $0.33 \pm 0.006$ & $52.2 \pm 0.7$ \\
Cel5L-p35 & CMC & $0.80 \pm 0.094$ & $164.6 \pm 10.8$ \\
& $p$ NPC & $0.19 \pm 0.02$ & $180.0 \pm 16.1$ \\
\hline
\end{tabular}

${ }^{*} \mathrm{CMC}, \% ; p \mathrm{NPC}, \mathrm{mM}$.

effects suggest the presence of CBM_3 had an insignificant impact on the effects of cations.

\section{Kinetics of the Truncated Enzymes}

The Lineweaver-Burk plots of Cel5L-p50 and Cel5L-p35 were linear (Fig. S2). $\mathrm{K}_{\mathrm{m}}$ values for $\mathrm{CMC}$ were similar, 0.77 and $0.80 \%$, respectively, and $\mathrm{V}_{\max }$ values were 143.3 and $164.6 \mathrm{U} / \mathrm{mg}$ protein, respectively. $\mathrm{K}_{\mathrm{m}}$ values for $p \mathrm{NPC}$ were 0.33 and $0.19 \mathrm{mM}$, and $\mathrm{V}_{\max }$ values were 52.2 and $180.0 \mathrm{U} / \mathrm{mg}$ protein, respectively (Table 4 ). These results showed that differences between substrate affinities or specific activities of the two enzymes for polymeric substrates such as CMC were not significant. Nonetheless, Cel5L-p50 had 1.7 times lower substrate affinity and 3.4 times less specific activity than Cel5L-p35 for the monomeric substrate $p$ NPC. We consider differences stemmed from the deletion of the CBM of Cel5L, which is composed of 80 amino acid residues from residues 353 to 434 . On the other hand, the CBM-truncated endoglucanase of B. subtilis JA18 was found to have greater $\mathrm{V}_{\max }$ and $\mathrm{K}_{\mathrm{m}}$ values (1.78- and 1.52-fold increase, respectively) for $\mathrm{CMC}$ than the CBM-containing endoglucanase [41].

\section{Carbohydrate Binding Properties of the Truncated Enzymes}

To analyze the binding capacity of CBM_3 in Cel5L-p50, residual enzyme activities were measured after binding to Avicel using purified Cel5L-p50 (containing CBM_3) and Cel5L-p35 (containing no CBM_3). Residual activity of Cel5L-p50 after binding to Avicel was significantly decreased by $70 \%$, whereas that of Cel5L-p35 increased to $140 \%$ (Table S1). Although the reason for this observed increase in Cel5L-p35 residual activity is not clear, these results suggest deletion of CBM_3 abolished binding ability to microcrystalline cellulose.

\section{Enzymatic Saccharification of Pretreated Biomasses}

The production of reducing sugar was investigated using pretreated reed and rice straw powders by adding purified Cel5L-p50 or Cel5L-p35 to a set of the commercial enzymes 

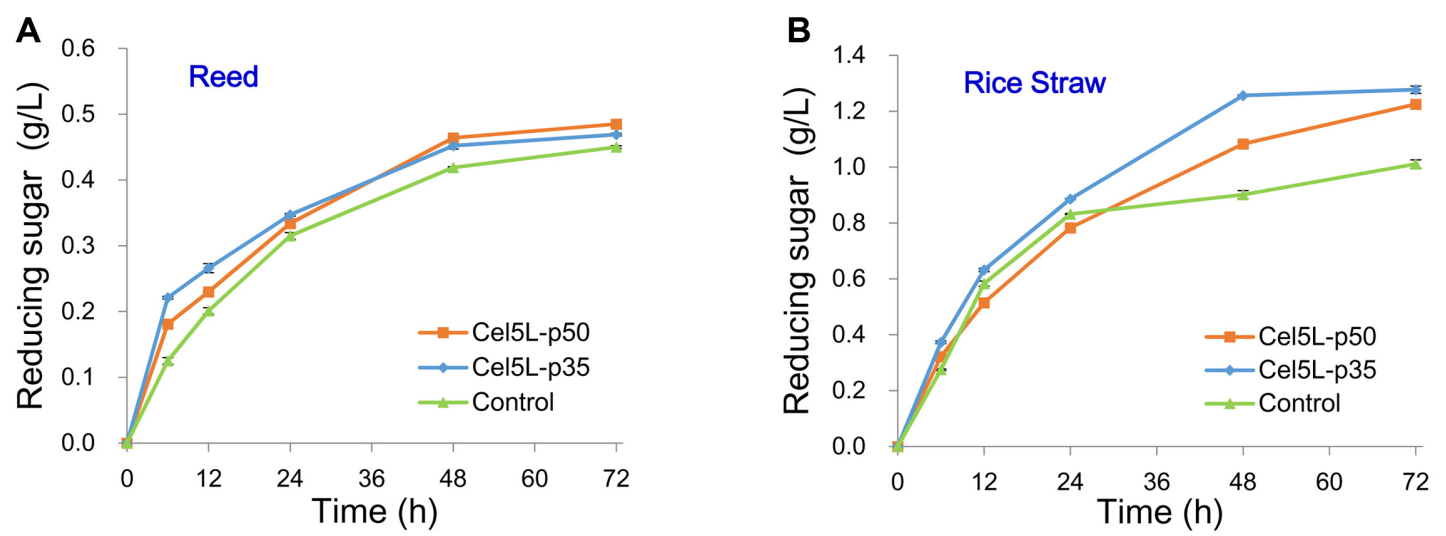

Fig. 4. Saccharification of pretreated reed (A) or rice straw (B) powders by purified Cel5L-p50 and Cel5L-p35.

(Celluclast 1.5L + Novozym 188). Productions of reducing sugar from pretreated reed or rice straw powders reached a maximum after 48 72 h (Fig. 4). The addition of Cel5L-p50 increased the saccharification values for reed and rice straw powders by $7.2 \%$ and $17.5 \%$, respectively (Fig. 4). When Cel5L-p35 was added to the commercial enzyme set, the saccharification values of the reed and rice straw powders were increased by $4.1 \%$ and $21.0 \%$, respectively (Fig. 4). Substrate specificities for pure $\beta$-1,4-glucan (CMC) and mixed-linked $\beta$-1,3-1,4-glucans (barley $\beta$-glucan or lichenan) and for small substrates probably contributed to observed differences between reed and rice straw powders. It has been previously reported saccharification efficiencies were increased by using pretreated materials [43], an optimized crude enzyme cocktail [44], and an ionic liquidtolerant cocktail for an ionic liquid-pretreated biomass [45]. In addition, Cel5L-p50 or Cel5L-p35 could be used as additives to improve the saccharification of lignocellulosic substrates, because they both enhance degree of saccharification of pretreated biomasses, regardless of CBM_3 deletion.

In conclusion, an endo- $\beta-1,4$-glucanase gene of Bacillus sp. KD1014 was cloned and its encoded products characterized. The endo- $\beta$-1,4-glucanase (Cel5L) belonged to GH5 and contained a CBM_3 module. Two truncated enzymes, that is, CBM_3-containing Cel5L-p50 and CBM_3-deleted Cel5Lp35, were purified from the transformant. Examination of the efficacies of these two truncated enzymes showed deletion of CBM_3 increased the thermostability, and affinity and reactivity for a small substrate ( $p N P C)$, but dramatically decreased binding affinity to Avicel. Notably, Cel5L-p35 enhanced saccharification of pretreated rice straw powder by $21.0 \%$ when added to a commercial enzyme preparation. These results suggest the two truncated forms might be potentially useful additives for the saccharification of lignocellulosic biomasses.

\section{Conflict of Interest}

The authors have no financial conflicts of interest to declare.

\section{References}

1. Lynd LR, Liang X, Biddy MJ, Allee A, Cai H, Foust T, et al. 2017. Cellulosic ethanol: status and innovation. Curr. Opin. Biotechnol. 45: 202211.

2. Zheng F, Tu T, Wang X, Wang Y, Ma R, Su X, et al. 2018. Enhancing the catalytic activity of a novel GH5 cellulase GtCel5 from Gloeophyllum trabeum CBS 900.73 by sitedirected mutagenesis on loop 6. Biotechnol. Biofuels 11: 76.

3. Lima AO, Quecine MC, Fungaro MH, Andreote FD, Maccheroni W Jr, Araújo WL, et al. 2005. Molecular characterization of a $\beta-1,4-e n d o g l u c a n a s e$ from an endophytic Bacillus pumilus strain. Appl. Microbiol. Biotechnol. 68: 5765.

4. Berlemont R, Martiny AC. 2016. Glycoside hydrolases across environmental microbial communities. PLoS Comput. Biol. 12: e1005300.

5. Berlemont R, Martiny AC. 2013. Phylogenetic distribution of potential cellulases in bacteria. Appl. Environ. Microbiol. 79: 1545-1554.

6. Talamantes D, Biabini N, Dang H, Abdoun K, Berlemont R. 2016. Natural diversity of cellulases, xylanases, and chitinases in bacteria. Biotechnol. Biofuels 9: 133.

7. Guo H, Chang Y, Lee DJ. 2018. Enzymatic saccharification of lignocellulosic biorefinery: research focuses. Bioresour. Technol. 252: 198-215.

8. Kim IJ, Lee HJ, Choi IG, Kim KH. 2014. Synergistic proteins for the enhanced enzymatic hydrolysis of cellulose by cellulase. Appl. Microbiol. Biotechnol. 98: 8469-8480. 
9. Park SH, Kim HK, Pack MY. 1991. Characterization and structure of the cellulase gene of Bacillus subtilis BSE616. Agric. Biol. Chem. 55: 441448.

10. Lee YJ, Kim BK, Lee BH, Jo KI, Lee NK, Chung $\mathrm{CH}$, et al. 2008. Purification and characterization of cellulase produced by Bacillus amyoliquefaciens DL-3 utilizing rice hull. Bioresour. Technol. 99: 378-386.

11. Santos CR, Paiva JH, Sforça ML, Neves JL, Navarro RZ, Cota J, et al. 2012. Dissecting structure-function-stability relationships of a thermostable GH5-CBM3 cellulase from Bacillus subtilis 168. Biochem. J. 441: 95-104.

12. Venditto I, Santos H, Sandy J, Sanchez-Weatherby J, Ferreira LM, Sakka K, et al. 2014. Crystallization and preliminary Xray diffraction analysis of a trimodular endo- $\beta$-1,4-glucanase (Cel5B) from Bacillus halodurans. Acta Crystallogr. F Struct. Biol. Commun. 70: 1628-1630.

13. Guan X, Chen P, Xu Q, Qian L, Huang J, Lin B. 2017. Expression, purification and molecular characterization of a novel endoglucanase protein from Bacillus subtilis SB13. Protein Expr. Purif. 134: 125-131.

14. Lee KD, Kim J, Kim H. 1996. Isolation and characterization of Bacillus sp. KD1014 producing carboxymethyl-cellulase. J. Microbiol. 34: 305-310.

15. Lee JP, Kim YA, Kim SK, Kim H. 2018. Characterization of a multimodular endo- $\beta-1,4$-glucanase (Ce19K) from Paenibacillus sp. X4 with a potential additive for saccharification. J. Microbiol. Biotechnol. 28: 588-596.

16. Petersen TN, Brunak S, von Heijne G, Nielsen H. 2011. SignalP 4.0: discriminating signal peptides from transmembrane regions. Nat. Methods 8: 785-786.

17. Bradford MM. 1976. A rapid and sensitive method for the quantitation of microgram quantities of protein utilizing the principle of protein-dye binding. Anal. Biochem. 72: 248-254.

18. Laemmli UK. 1970. Cleavage of structural proteins during the assembly of the head of bacteriophage T4. Nature 227: 680-685.

19. Yang MJ, Lee HW, Kim H. Enhancement of thermostability of Bacillus subtilis endoglucanase by error-prone PCR and DNA shuffling. Appl. Biol. Chem. 60: 73-78.

20. Miller GL. 1959. Use of dinitrosalicylic acid reagent for determination reducing sugar. Anal. Chem. 31: 426428.

21. Jeong YS, Na HB, Kim SK, Kim YH, Kwon EJ, Kim J, et al. 2012. Characterization of xyn10J, a novel family 10 xylanase from a compost metagenomic library. Appl. Biochem. Biotechnol. 166: 1328-1339.

22. Shin ES, Yang MJ, Jung KH, Kwon EJ, Jung JS, Park SK, et al. 2002. Influence of the transposition of the thermostabilizing domain of Clostridium thermocellum xylanase (XynX) on xylan binding and thermostabilization. Appl. Environ. Microbiol. 68: 3496-3501.

23. Lin L, Meng X, Liu P, Hong Y, Wu G, Huang X, et al. 2009. Improved catalytic efficiency of endo-beta-1,4-glucanase from Bacillus subtilis BME-15 by directed evolution. Appl.
Microbiol. Biotechnol. 82: 671679.

24. Robson LM, Chambliss GH. 1987. Endo-beta-1,4-glucanase gene of Bacillus subtilis DLG. J. Bacteriol. 169: 20172025.

25. Endo K, Hakamada Y, Takizawa S, Kubota H, Sumitomo N, Kobayashi $\mathrm{T}$, et al. 2001. A novel alkaline endoglucanase from an alkaliphilic Bacillus isolate: enzymatic properties, and nucleotide and deduced amino acid sequences. Appl. Microbiol. Biotechnol. 57: 109116.

26. Henrissat B, Claeyssens M, Tomme P, Lemesle L, Mornon JP. 1989. Cellulase families revealed by hydrophobic cluster analysis. Gene. 81: 8395.

27. Ducros V, Czjzek M, Belaich A, Gaudin C, Fierobe HP, Belaich JP, et al. 1995. Crystal structure of the catalytic domain of a bacterial cellulase belonging to family 5 . Structure 9: 939949.

28. Rattu G, Joshi S, Satyanarayana T. 2016. Bifunctional recombinant cellulase-xylanase (rBhcell-xyl) from the polyextremophilic bacterium Bacillus halodurans TSLV1 and its utility in valorization of renewable agro-residues. Extremophiles 6: 831-842.

29. Ruiz DM, Turowski VR, Murakami MT. 2016. Effects of the linker region on the structure and function of modular GH5 cellulases. Sci. Rep. 6: 28504.

30. Boraston AB, Kwan E, Chiu P, Warren RA, Kilburn DG. 2003. Recognition and hydrolysis of noncrystalline cellulose. J. Biol. Chem. 8: 61206127.

31. Jung KH, Lee KM, Kim H, Yoon KH, Park SH, Pack MY. 1998. Cloning and expression of a Clostridium thermocellum xylanase gene in Escherichia coli. Biochem. Mol. Biol. Int. 44: 283-292.

32. Feng JX, Karita S, Fujino E, Fujino T, Kimura T, Sakka K, et al. 2000. Cloning, sequencing, and expression of the gene encoding a cell-bound multidomain xylanase from Clostridium josui, and characterization of the translated product. Biosci. Biotechnol. Biochem. 64: 614-2624.

33. Pastor FI, Pujol X, Blanco A, Vidal T, Torres AL, Díaz P. 2001. Molecular cloning and characterization of a multidomain endoglucanase from Paenibacillus sp BP-23: evaluation of its performance in pulp refining. Appl. Microbiol. Biotechnol. 55: 61-68.

34. Lee JP, Lee HW, Na HB, Lee JH, Hong YJ, Jeon JM, et al. 2018. Characterization of truncated endo- $\beta$-1,4-glucanases from a compost metagenomic library and their saccharification potentials. Int. J. Biol. Macromol. 115: 554-562.

35. Kim H, Kim SF, Ahn DH, Lee JH, Pack MY. 1995. Internal cleavage of Bacillus subtilis BSE616 endo- $\beta-1,4-$ glucanase expressed in Escherichia coli. J. Microbiol. Biotechnol. 5: 26-30.

36. Aspeborg H, Coutinho PM, Wang Y, Brumer 3rd. H, Henrissat B. 2012. Evolution, substrate specificity and subfamily classification of glycoside hydrolase family 5 (GH5). BMC Evol. Biol. 12: 186.

37. Liberato MV, Silveira RL, Prates ÉT, de Araujo EA, Pellegrini VO, Camilo CM, et al. 2016. Molecular characterization of a 
family 5 glycoside hydrolase suggests an induced-fit enzymatic mechanism. Sci. Rep. 6: 23473.

38. Posta K, Béki E, Wilson DB, Kukolya J, Hornok I. 2005. Cloning, characterization and phylogenetic relationships of cel5B, a new endoglucanase encoding gene from Thermobifida fusca. J. Basic Microbiol. 44: 383399.

39. Akita M, Kayatama K, Hatada Y, Ito S, Horikoshi K. 2005. A novel $\beta$-glucanase gene from Bacillus halodurans C-125. FEMS Microbiol. Lett. 248: 9-15.

40. Dadheech T, Shah R, Pandit R, Hinsu A, Chauhan PS, Jakhesara S, et al. 2018. Cloning, molecular modeling and characterization of acidic cellulase from buffalo rumen and its applicability in saccharification of lignocellulosic biomass. Int. J. Biol. Macromol. 113: 7381.

41. Wang Y, Yuan H, Wang J, Yu Z. 2009. Truncation of the cellulose binding domain improved thermal stability of endo-beta-1,4-glucanase from Bacillus subtilis JA18. Bioresour.
Technol. 100: 345349.

42. Dhar H, Kasana RC, Dutt S, Gulati A. 2015. Cloning and expression of low temperature active endoglucanase EG5C from Paenibacillus sp. IHB B 3084. Int. J. Biol. Macromol. 81: 259-266.

43. Kim DU, Kim HJ, Jeong YS, Na HB, Cha YL, Koo BC, et al. 2015. Enhanced saccharification of reed and rice straws by the addition of $\beta$-1,3-1,4-glucanase with broad substrate specificity and calcium ion. J. Korean Soc. Appl. Biol. Chem. 58: 29-33.

44. Singh A, Bishnoi NR. 2012. Optimization of enzymatic hydrolysis of pretreated rice straw and ethanol production. Appl. Microbiol. Biotechnol. 93: 1785-1793.

45. Park JI, Steen EJ, Burd H, Evans SS, Redding-Johnson AM, Batth T, et al. 2012. A thermophilic ionic liquid-tolerant cellulase cocktail for the production of cellulosic biofuels. PLoS One 7: e37010. 